\title{
Impact of cyclones over kamchatka on electron distribution in the ionosphere
}

\author{
Vadim Bogdanov ${ }^{1, \star}$, Alexandr Kaysin ${ }^{2, \star \star}$, and Alexandr Romanov ${ }^{3, \star \star \star}$ \\ ${ }^{1}$ Institute of Cosmophysical Research and Radio Wave Propagation FEB RAS, 684034, Paratunka, Mirnaya \\ str., 7, Russia \\ ${ }^{2}$ Institute of Cosmophysical Research and Radio Wave Propagation FEB RAS, 684034, Paratunka, Mirnaya \\ str., 7, Russia \\ ${ }^{3}$ OAO "Russian Space Systems"
}

\begin{abstract}
The paper presents the results of investigation of cyclone impact on ionosphere parameters. Ionosphere state was observed by automatic sounding equipment applying low-orbital navigation spacecrafts in the conditions of low seismicity.
\end{abstract}

\section{Introduction}

Kamchatka region is located in the area of junction of the Asian continent and the Pacific Ocean, and it is characterized by increased seismic activity. The whole territory is within the zone of intensity 5-9 earthquakes (12-grade seismic intensity scale). Thus, the search for the precursors of catastrophic seismic events to make their forecast is very important. The well-known factor is the relation of the processes occurring on the Sun and in the Earth's lithosphere with the processes in the ionosphere manifesting as registered precursors (see, for example, the monograph [1] and the references there). However, registration of a reliable forecast feature of a seismic event in the ionosphere parameter behavior faces some difficulties which are associated with the fact that the Earth's atmosphere is a dynamic system affected by different physical external processes. Consequently, ionospheric parameter variations cannot be explained completely not taking into account the influence of the atmosphere lower layers. Thus, physical processes generated in the lower and middle atmosphere may affect the parameters in the upper layers including ionosphere. Such atmospheric phenomena as cyclones may have some impact on the ionosphere state in a varying degree. Since the Kamchatka territory is washed by the Pacific Ocean, by the Okhotsk and the Bering Seas, which are the zones of increased cyclone activity, Kamchatka may be considered as a field test site for investigation of the impact of cyclone activity on the processes in the ionosphere when the corresponding measurement systems are available. By the present moment, a cycle of work has been carried out. The relations between wave disturbances in the atmosphere and weather conditions were under investigation. Wave disturbances in ionospheric parameters during storm passage were observed [2]. Quasiperiodic vibrations were

\footnotetext{
^e-mail: vbogd@ikir.ru

$\star \star$ e-mail: kaisin@mail.ru

$\star \star \star$ e-mail: romulas@mail.ru
} 
detected during the propagation of a strong thunderstorm [3]. At present time, there are papers devoted to the investigation of possible impact of tropical cyclones on different layers of the ionosphere. Such disturbances were registered by different methods. Mid-scale traveling ionospheric disturbances (TID) with the period of about 20 minutes were detected during propagation of storms by the measurements of Doppler frequency shift in the ionosphere [4]. It was shown that at the distance of about 3-5 thousand of kilometers from a cyclone center, changes of $f_{0} F 2$ parameter by $10-20 \%$ were observed by ionosondes of vertical and oblique sounding [5]. The authors of the papers think that increase [6] or decrease [7] of the critical frequency $f_{0} F 2$ may be associated with a delay of the moment of measurement relatively the time of cyclogenesis. In the papers $[8,9]$, time intervals of increase of signal spectrum power at definite frequencies were detected. Increase of acoustic gravitational wave (AGW) activity by $20-30 \%$ was determined at the stage of fast change of hurricane intensity by GPS measurements. However, there are some publications where ionosphere response was not detected [11]. In this paper, a cycle of investigations of tropospheric cyclone effect on ionopheric parameters is suggested on the example of winter and spring cyclones. This survey applies the data obtained by the method of tomographic sounding by a chain of tomographic stations located on Kamchatka peninsula. The peculiarity of this work is the location of the receiving stations for tomographic sounding in the area of cyclone effect.

\section{Description of the method}

Radio tomographic sounding of the ionosphere is carried out over the territory of Kamchatka peninsula by ray radio tomography. The tasks of ray radio tomography are practically solved by satellites and several receivers. Several stations for registration of navigation signals are arranged on the Earth surface in the plane which corresponds to the angles of orbital inclination of satellites. In case of application of "Tsikada/Tranzit" space systems, the orbital inclination of which is $83^{\circ}-90^{\circ}$ degrees, ground receiving stations for navigation signals should be arranged in meridian direction. On the ground, electron content on the propagation path of a navigation signal may be estimated by the phases of signals with the frequencies of 150 and $400 \mathrm{MHz}$. During the time of satellite flying over the extended system of ground stations, a series of measurements is carried out. For each station of registration of a navigation signal we determine

$$
T E C=\int_{p} N_{e} d s
$$

, (where TEC is the total electron content along the path of signal propagation between a source and a receiver $p, N_{e}$ is the electron content), on an element of propagation path $d s$. Then the tomographic crosscut is reconstructed by an inverse problem [12,13]. Fig. 1 shows a scheme of realization of the method of ionosphere tomographic sounding which allows us to restore electron concentration in the upper atmosphere. Low-orbital navigation satellites of "Kosmos" type were used as sources of coherent signals. It allows us to reproduce the concentration vertical distribution along the track of a satellite with good resolution (25 km height and $50 \mathrm{~km}$ latitude). Ground receivers of signals are located in Paratunka (Par), Mil'kovo (Ml), Esso (Ess) in sub-meridian direction $\left(158^{\circ} 31^{\prime} \mathrm{E}\right)$. The receiving stations operate automatically.

\section{Analysis of experimental results}

To study the ionosphere response, we chose the cyclones which passed over Kamchatka within the period from January 2012 to February 2014 (Table 1) in the conditions of calm and moderately calm 


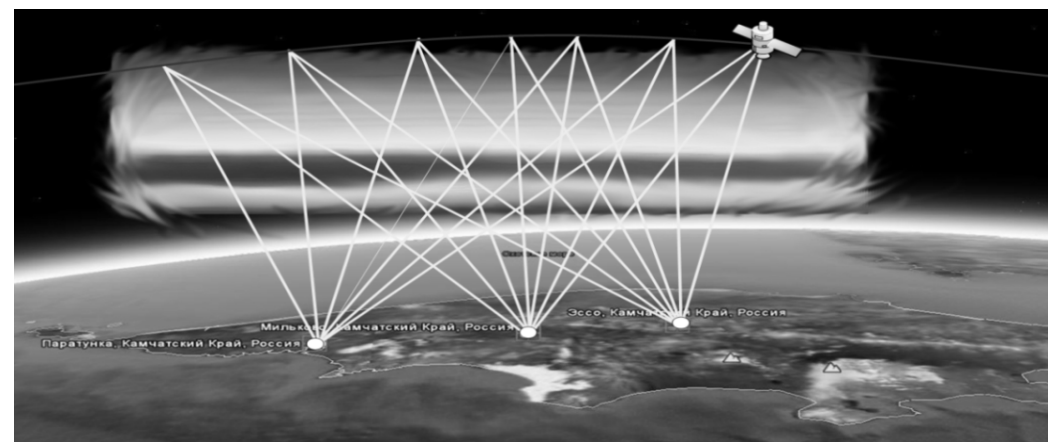

Figure 1. Scheme of arrangement of receiving stations and sounding signal propagation.

magnetic state $(K \leq 17)$. During the passage of the cyclones there were no strong earthquakes in Kamchatka region and the seismic regime corresponded to the background mode. It gives us grounds to hope that if there are effects of cyclone influence on the ionosphere, this influence is not masked by the processes occurring in the lithosphere of the seismically active region. The left part of the Table 1 defined as "Day with cyclone" shows the date of its passage, time of satellite fly-over (UT), total index of magnetic activity $(\mathrm{K})$ on the mentioned date at "Paratunka" magnetic station. The second part of the Table ("Day without cyclone") gives the information on the closest to the cyclone reference day for which electron meridian distribution was determined for comparison. The time of satellite fly-over on the reference day was chosen to be the most close to the time of fly-over on the day of a cyclone. As an example, Fig. 2 illustrates synoptic charts and tomograms of electron sub-meridian height distributions for two days with the cyclone (January 18, 2013) and without it (January 12, 2013). The tomograms show the latitude in degrees and the stations of satellite data registration Par, $M l$, Ess, along the x-axis and the height in $\mathrm{km}$ along the y-axis. The scale of electron concentration distribution is to the right from the tomograms. Tomograms are taken within the latitude range of $48.01^{\circ}-61.52^{\circ} \mathrm{N}$.

Table 1.

\begin{tabular}{|l|l|l|l|l|l|}
\hline \multicolumn{3}{|c|}{ Day with cyclone } & \multicolumn{3}{c|}{ Day without cyclone } \\
\hline Dat & $\begin{array}{l}\text { Time of satel- } \\
\text { lite fly-over, } \\
\text { UT }\end{array}$ & Total K-index & Date & $\begin{array}{l}\text { Time of satel- } \\
\text { lite fly-over, } \\
\text { UT }\end{array}$ & Total K-index \\
\hline 13.01 .2012 & $15: 10$ & 9 & 09.01 .2012 & $15: 06$ & 10 \\
\hline 01.04 .2012 & $12: 49$ & 14 & 29.03 .2012 & $12: 32$ & 4 \\
\hline 18.01 .2013 & $16: 00$ & 16 & 12.01 .2013 & $16: 20$ & 2 \\
\hline 03.02 .2013 & $18: 09$ & 7 & 31.01 .2013 & $18: 32$ & 1 \\
\hline 17.02 .2013 & $12: 33$ & 17 & 12.02 .2013 & $13: 07$ & 9 \\
\hline 18.02 .2013 & $09: 20$ & 5 & 15.02 .2013 & $09: 46$ & 7 \\
\hline 31.01 .2014 & $14: 15$ & 0 & 25.01 .2014 & $14: 40$ & 13 \\
\hline 05.02 .2014 & $17: 05$ & 9 & 25.01 .2014 & $17: 33$ & 13 \\
\hline
\end{tabular}






a)
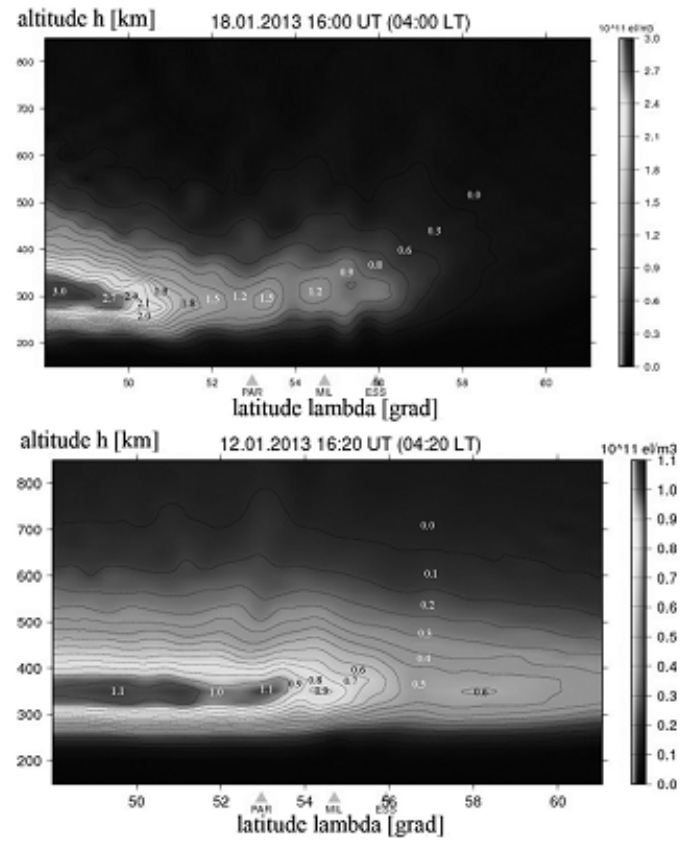

b)

Figure 2. Cyclone on January 18, 2013 a) Synoptic chart corresponds to 12 UT. Eastern wind reached $30 \mathrm{~m} / \mathrm{s}$ at the height of $5 \mathrm{~km}$. Cyclone center was located in the Southern part of the peninsular at $\sim 48^{\circ} \mathrm{N}(12 \mathrm{UT}$ ) b) On January 18, 2013 at 16:00 UT ionospheric plasma turbulization is observed with clearly defined plasma formation within the latitude range of $48^{\circ}-49^{\circ} \mathrm{N}$ and the height range of $290-350 \mathrm{~km}$ with the latitude increase (January 12, 2013 is the reference day).

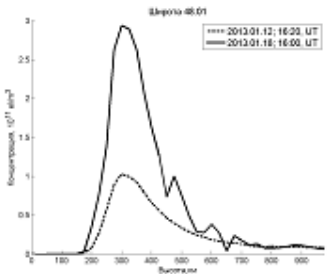

a)

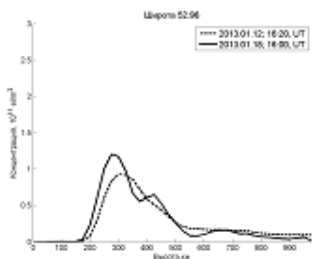

b)



c)

Figure 3. Profile of electron density distribution in the ionosphere on January 18, 2013 at 16:00 UT (04:00 LT) (solid line) for three latitudes in comparison to the reference day on January 12, 2013 (dashed line).

Table 2 shows the highest values of electron concentration for the three chosen latitudes of $48.01^{\circ}$ $\mathrm{N}, 52.96^{\circ} \mathrm{N}$ and $61.52^{\circ} \mathrm{N}$ for the cyclone under analysis and the corresponding reference day. 
Table 2. Highest value of electron concentration of the ionosphere, $\mathrm{el} / \mathrm{m}^{3}\left(\times 10^{11}\right)$

\begin{tabular}{|l|l|l|l|}
\hline Satellite fly-over/ Latitude & $48.01^{\circ} \mathrm{N}$ & $52.96^{\circ} \mathrm{N}$ & $61.52^{\circ} \mathrm{N}$ \\
\hline $12.01 .2013 ; 16: 20 \mathrm{UT}$ & 1,0287 & 0,9313 & 1,0287 \\
\hline $18.01 .2013 ; 16: 00 \mathrm{UT}$ & 2,9366 & 1,2030 & 0,1486 \\
\hline
\end{tabular}

\section{Conclusions}

The analysis of cyclone development showed that:

- Increases in electron concentration are observed for five out of eight cyclones compared to the reference days near the cyclone centers.

- The highest turbulization of the ionosphere is observed just over the cyclone center area which is characterized by steep gradients in electron distributions.

- Electron concentration change in the ionosphere may be explained by mechanical momentum transfer from the lower layers of the ionosphere and neutral atmosphere [14] to the heights of F-layer and by cyclone-induced AGW effect.

- Further investigations of cyclone impact on the ionosphere are necessary to collect statistics, to develop physical models and to determine the mechanism of transfer of cyclone rotational motion momentum to ionospheric heights.

The work is supported by RFBR Grant No. 11-05-00915, by Presidium RAS Program No. 121-P22-01 and FEB RAS Program "Satellite monitoring of the Far East for fundamental scientific investigations of FEB RAS".

\section{References}

[1] Pulinets S.A. et al., Prognoz zemletryaseniy vozmozhen?! (Trovant, 2014) 144

[2] Baker Donald M., Davies Kenneth, Journal of Geophysical Research 70 Ionospheric Effects Observed around the Time of the Alaskan Earthquake of March 28, 1964, 2251-2253 (1965)

[3] Prasad S.S., Schneck L.J., Davies K., Journal of Atmospheric and Terrestrial Physics 37 Ionospheric disturbances by severe tropospheric weather storms, 1357-1363 (1975)

[4] Xiao Z. et al, Journal of Geophysical Research. Space Physics 112 Morphological features of ionospheric response to typhoon, A04304 (2007)

[5] Vanina-Dart L. B., Romanov A. A.,Sharkov E. A, Journal Geomagnetism and Aeronomy. 51 Influence of a tropical cyclone on the upper ionosphere according to tomography sounding data over Sakhalin Island in November 2007, 774-782 (2011)

[6] Rice D.D. et al., Journal Radio Science. 47 Typhoon Melor and ionospheric weather in the Asian sector: A case study , (2012)

[7] Liu Y.-M., Wang J.-S., Suo Y.-C., Journal Adv. Geosci. 29 Effects of typhoon on the ionosphere, 351-360(2006)

[8] Mikhailov Yu.M. et al., Journal Geomagnetism and Aeronomy. 45 Possible atmospheric effects in the lower ionosphere according to atmospheric radio noise observations on Kamchatka during tropical cyclones, 778-792(2005)

[9] Chernigovskaya M.A. et al., Journal Issledovanie Zemli iz kosmosa. Issledovanie svyazi korotkoperiodnykh vremennykh variatsiy parametrov ionosfery $\mathrm{v}$ Severo-Vostochnom regione Rossii s proyavleniyami tropicheskikh tsiklonov, 32-41 (2010) 
[10] Zakharov V.I., Kunitsyn V.E, Journal Geomagnetism and Aeronomy. 52 Regional features of atmospheric manifestations of tropical cyclones according to ground- based GPS network data, 533-545 (2012)

[11] Afraimovich E.L. et al, Journal Geomagnetism and Aeronomy. 48 Variations in the total electron content during the powerful typhoon of August 5-11, 2006, near the southeastern coast of China, 674-679 (2008)

[12] Andreeva E.S., Kunitsyn V.E., Tereshchenko E.D., Journal Geomagnetism and Aeronomy. 32 Fazoraznostnaya tomografiya ionosfery, 104-110 (1992)

[13] Romanov A.A. et al, Journal Sovremennye podkhody k sozdaniyu avtomatizirovannoy sistemy registratsii ionosfernykh predvestnikov zemletryaseniy po sputnikovym dannym. Fazoraznostnaya tomografiya ionosfery, 167-172 (2006)

[14] Danilov A.D. et al., Meteorologicheskie effekty v ionosfere (Gidrometeoizdat, 1987) 